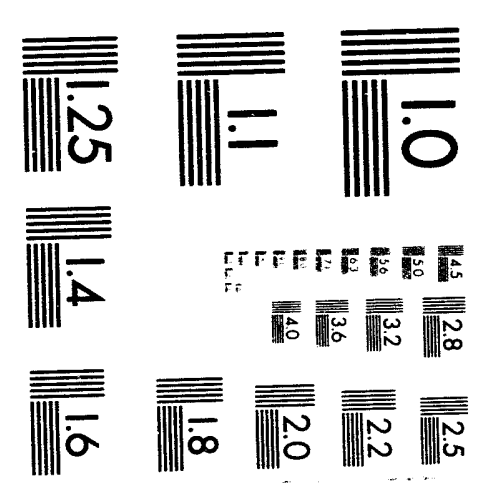



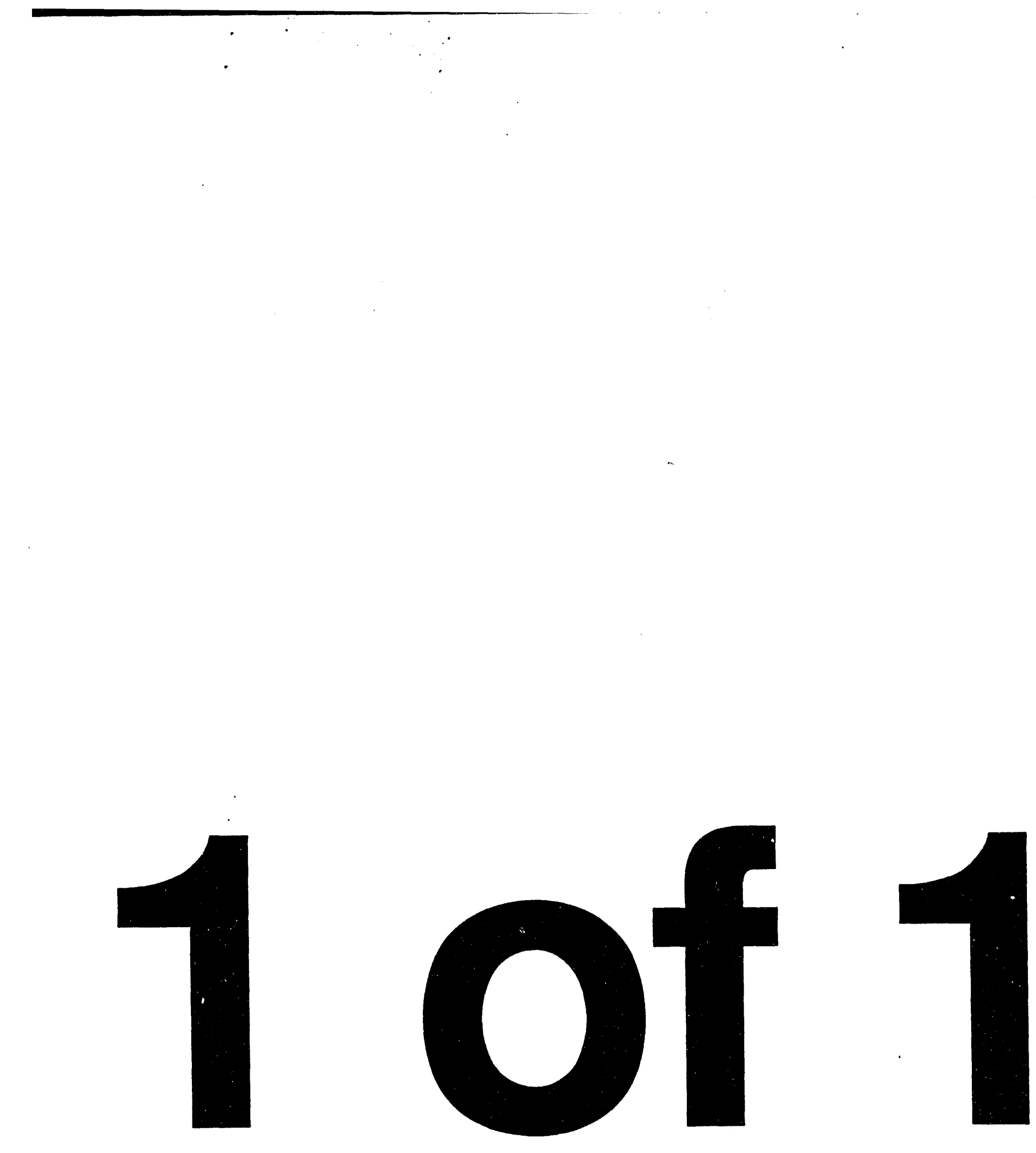


\section{EBR-II Axial Temperature Distributions Measured During In-Vessel Natural Circulation Experiments*}

W. A. Ragland and E. E. Feldman

Telephone: (708) 972-3076

Argonne National Laboratory

Argonne, Illino is 60439

U. S. Government purposes.

*Work supported by the U.S. Department of Energy, Nuclear Energy Programs under Contract W-31-109-ENG-38.

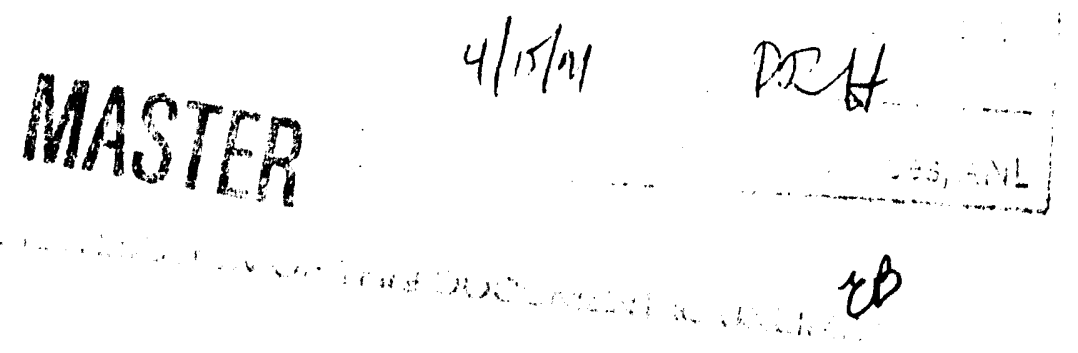


The Experimental Breeder Reactor II is located in a cylindrical pool of liquid sodium which is part of the cold-leg of the primary flow circuit. A vertical string of 32 thermocouples spans the $8 \mathrm{~m}$ tank height, at each of two diametrically opposed locations in the primary tank. Local temperatures were measured with these 64 thermocouples during dynamic tests. The instantaneous spacial temperature distribution obtained from a string of thermocouples can be viewed on a personal computer. The animation which results from displaying successive spacial distributions provides a very effective way to quickly obtain physical insights. The design of the two strings of thermocouples, the software used to create the animation, measured data from three different types of tests - two unprotected reactor transients, and one with the reactor at decay power levels and the reactor cover lifted, are discussed. 
The pool-type reactor is the prototype design for commercial-scale I.MRs in the U.S. In this design the reactor is in a large pool of liquid sodium. Physical dividers within the primary pool separate it into a hot-pool and a coldpool. The primary sodium flow goes from the cold-pool through the reactor to the hot-pool, then through the intermediate heat exchangers, IHXs, and then back to the cold-pool. The dynamic behavior of these pools impacts primary circuit thermal transport times and reactivity feedbacks.

The Experimental Breeder Reactor II, EBR-II, is also in a large pool of liquid sodium. The primary tank is not divided into separate pools. The primary sodium flow goes from the primary p001, through the reactor, and then through a stainless steel pipe which connects the reactor to the single IHX. After the flow traverses the IHX, it returns to the primary pool. Here, too, the dynamic behavior of the pool impacts transport times and feedbacks. While it is unreasonable to expect the EBR-II pool to behave identically to either a hot or a cold pool, the methods and insights obtained from the EBR-II experience will be helpful in understanding pool behavior.

\section{THE EBR-II REACTOR PLANT}

The EBR-II plant is located in Idaho and was designed by the Argonne National Laboratory who operates it for the U. S. Department of Energy. The EBRII has been in operation since 1964 and has served as a fast-flux irradiation facility since 1967 and also as a dynamic test facility since $1974 .^{1}$ The plant 
produces about $20 \mathrm{MW}$ of electricity when the reactor is operated at its full 62.5 MW nameplate power.

The internal dimensions of the primary tank, figure 1 , are about $8 \mathrm{~m}$ in both diameter and height. Argon cover gas occupies the top $0.5 \mathrm{~m}$ of this volume. Sodium is drawn from the primary tank through the two main coolant pump inlets, located $180^{\circ}$ apart on opposite sides of the reactor vessel. The primary flow travels downward through the shell-side of the IHX and exits directly back into the primary pool. The exit of the IHX and the top of the reactor vessel are both located at about $5 \mathrm{~m}$ from the bottom of the sodium pool. The elevation of the pump inlets is about $1 \mathrm{~m}$ above the IHX outlet. Because the No. 1 pump inlet is much closer to the IHX outlet than is the No. 2 pump, there is a flow baffle between the No. 1 pump inlet and the IHX outlet to make the lengths of the two flow paths from the IHX to the pumps more equal.

The reactor cover can be raised vertically $2.7 \mathrm{~m}$ during fuel handling to within $0.6 \mathrm{~m}$ of the bottom of the primary tank cover as shown in figure 2 . Then there is $1.7 \mathrm{~m}$ between the top of the reactor vessel and the bottom of the reactor vessel cover. The cover itself is $1.0 \mathrm{~m}$ thick, not including a cylindrical flow baffle attached to its underside, and is $2.3 \mathrm{~m}$ in diameter. When the cover is down, the height of the reactor outlet plenum is $0.6 \mathrm{~m}$. When the cover is raised, the depth of the cavity increases to $1.6 \mathrm{~m}$.

The control rod drives rest on the top of the primary tank cover and the control rod extensions traverse the upper portion of the sodium pool to the reactor. There are also two safety rods which provide additional scram capability and are also functional during fuel handling. The configuration of control and safety rods enables thermal elongation of the control rod extensions or of the safety rod vertical support rods to remove reactivity from the reactor. 
$-5-$

Similarly, the thermal elongation of the lateral wall of the primary tank can cause reactivity to be added.

\section{INSTRUMENTATION}

Two thermocouple probes were installed in EBR-II, figure $3,180^{\circ}$ apart at approximately $1 / 3$ and $2 / 3$ of the radial distance between the reactor vessel and the primary tank. Each probe consists of 32 thermocouples eventy spaced at 0.23 $\mathrm{m}$ intervals from the argon cover gas space to within $0.5 \mathrm{~m}$ of the tank bottom. The top thermocouple in each probe is in the argon cover gas. The remaining 31 thermocouples are immersed directly in the sodium. The probes are identified as the $F$-probe and G-probe to conform with the existing EBR-II nozzle designation.

The probes were constructed of three sections of stainless steel pipe which provide support and alignment for the thermocouples and provided protection for the thermocouple leads during installation. This design is more robust than that for the normal thermocouple rakes. This construction method was selected to allow long term use if the probes were included in the EBR-II instrumentation on a permanent basis. The individual thermocouples pass through small holes in the pipe and are exposed directly to the sodium. The holes for the thermocouples are arranged in two rows $180^{\circ}$ apart with the thermocouples alternately exiting through each row. The thermocouples extend approximately $1.27 \mathrm{~cm}$ beyond the pipe to minimize temperature response effects due to the mass of the pipe. Although the probes were designed for a specific test program and had their own separate data acquisition system, eventually, the probes were accepted as a permanent addition to the EBR-II plant and were incorporated in the EBR-II data acquisition system. 
Since the probe data represents spacial temperature distributions which vary with time, we chose to use animation methods, which are available in the popular press ${ }^{2}$ and could be implemented with inexpensive software. ${ }^{3}$ When a series of static spacial graphs representing successive values of time are plotted on a computer monitor so that each successive plot replaces the last, an animation results. Since it is not practical to show in a paper the volume of data from both probes used in the animation, instantaneous plots of the data from the G-probe are used to provide a "snapshot" of the temperature profiles in the EBR-II primary tank. Data from the top thermocouple has bet.l eliminated because it is in the gas space above the sodium pool. Vertical distance was represented on the ordinate and temperature was represented on the abscissa. The time of the data is used to differentiate the multiple profiles on each figure. Insight gained from viewing the animation is described in the text.

\section{TEMPERATURE PROFILES AT POWER AND SHUTDOWN}

The different steady-state tank temperature profiles due to power level can be seen in figure 4. This data was taken from the reactor shutdown prior to the cover lift test. For the other tests, a similar temperature profile exists with an offset for the lower average initial tank temperatures of $343^{\circ} \mathrm{C}\left(650^{\circ} \mathrm{F}\right)$ rather than the $371^{\circ} \mathrm{C}\left(700^{\circ} \mathrm{F}\right)$ of the cover lift test. The elevation in the tank is measured from the top of the primary tank. At full power, steady-state temperature profiles were similar for both probes, although there were significant local temperature fluctuations with time. The temperature was fairly uniform in the lower half of the tank and increased monotonically toward the top of the pool. This temperature increase is about $22^{\circ} \mathrm{C}\left(40^{\circ} \mathrm{F}\right)$. The temperature 
profile divides the tank into two distinct regions. The part of the tank above $2.2 \mathrm{~m}$ shows the steep temperature gradient which is due to the 1 arge amount of heat given off by the reactor outlet pipe. The local temperatures near the outlet pipe are probably much higher than those recorded by the probes, since the probes are far away from the pipe. The remainder of the tank has a much snaller temperature gradient. It is possible to divide this region still further in a moderate temperature gradient from $2.2 \mathrm{~m}$ to approximately $5 \mathrm{~m}$ with an extremely small gradient to flat temperature profile in the bottom $3 \mathrm{~m}$ of the tank. The temperature profile with the reactor shutdown but primary pumps operating a full flow demonstrates that there is sufficient mixing in the primary tank to provide a uniform temperature in the entire primary tank at decay heat power levels.

\section{UNPROTECTED LOSS-OF-HEAT-SINK TEST}

The unprotected loss-of-heat-sink, LOHS, test was designed to represent a bounding case for a whole class of hypothetical LMR plant accidents. In this accident the reactor is in steady-state operation at full power when two major independent failures occur. First, the plant loses its ability to remove power from the primary system. Second, the reactor protection system fails to scram as a result of the first failure. When this test was conducted the main purpose was to demonstrate inherent reactor shutdown mechanisms. Data was also collected from the two tank probes to observe stratification in the pool. This test is particularly useful for pool studies because of the large changes in primary tank temperature, on the order of $50^{\circ} \mathrm{C}\left(90^{\circ} \mathrm{F}\right)$. 
$-8-$

Since the test transient is fully described elsewhere ${ }^{4}$, only a brief description is needed here. Actually, this test was conducted twice, SHRT B302 on March 30, 1986 when there was sufficient time to collect data for $51 / 2$ hours and SHRT B302R on April 3, 1986 when time constraints limited the test to $11 / 2$ hours. While the data in the reference is for the latter test, the earlier test is of greater interest here because of the longer-term effects in the primary tank. The initial reactor inlet temperature for the test was $343^{\circ} \mathrm{C}\left(650^{\circ} \mathrm{F}\right)$ instead of the normal $371^{\circ} \mathrm{C}\left(700^{\circ} \mathrm{F}\right)$ value. The initial reactor power was $60 \mathrm{MW}$ and the reactor coolant temperature rise was at or near the normal value of $102^{\circ} \mathrm{C}$ $\left(183^{\circ} \mathrm{F}\right)$.

The test was initiated by tripping the power supply to the pump in the secondary-flow loop and then manually controlling the alternate power supply to the pump to reduce the secondary flow rate to very near to zero. Had manual control not been used, natural convection would have resulted in a secondary flow rate of about 5 to $8 \%$ of its initial value.

With the secondary flow essentially stopped, heat transfer from the primary system to the rest of the plant via the IHX is virtually eliminated. Thus, the primary sodium exits the IHX at the same temperature it entered. As this hot sodium exits the IHX it causes the primary tank sodium temperature to rise along with the reactor inlet temperature. The rising reactor inlet temperature causes reactivity to be removed from the reactor. This reduces the reactor power at a sufficient rate to cause the reactor outlet coolant temperature to decrease. Eventualiy, as the reactor power goes to zero, the reactor inlet and outlet temperatures approach an asymptotic temperature.

Figure 5 shows the temperature profiles in the primary tank during SHRT B302. The rapid initial increase of sodium temperature within the upper half of 
the tank is seen in the profile at 13:07 as compared to the steady-state profile at 13:05. The lower half of the tank is affected only minimally in this short time interval. It should be noted that the thermocouples which are used by the EBR-II data acquisition system to measure and display average primary tank temperature are located at the elevation of the primary pump inlets which corresponds to $2.3 \mathrm{~m}$ on this figure. Thus the reactor inlet temperature rises much faster than the average integrated over the entire depth of the tank. The temperature profiles at $13: 12,13: 24$ and 14:00 show the general heatup of the primary tank and also show the progression of heating the tank from top to bottom. The test appeared essentially complete at 14:00 as shown in figure 5 .

The animation dramatically showed the rapid increase in tank temperatures early in the transient, figure 5. The temperature profiles are seen to move sideways rapidly across the screen. Because the IHX outlet is near the middle of the tank and the pump inlets are above the middle, changes in the top portion of the profile tend to lead those in the bottom portion. Then the top portion retreats as the bottom portion advances. This is because 1) the primary pumps are at full flow throughout the test and mixing within the tank tends to cause temperature differences to disappear and 2) temperatures inside the reactor outlet pipe are decreasing and cooling the surrounding region.

At about $1.7 \mathrm{~h}$ into the transient it seemed that a final steady-state near zero-power condition had been well established in which the reactor inlet and outlet temperatures were essentially equal. The temperature profile was uniform as shown in curve 14:00 of figures 5 and 6 . After 14:40 an anomaly occurred in which the reactor inlet and outlet temperatures and their difference increased as the reactor power increased to about $2.3 \mathrm{MW}$. Less than an hour later, the two temperatures were essentially coincident again, but $10^{\circ} \mathrm{C}\left(18^{\circ} \mathrm{F}\right)$ higher as shown 
$-10-$

in figure 6, and the power returned to near zero. The temperature profile at 15:00 has the same shape as the two profiles at 14:00 and 16:00 which represent the apparent steady state and actual steady state conditions, respectively. During this time the tank temperature profile remained essentially flat with only a small "tail" at the bottom of the tank probably due to the lag in heatup of the structure near the bottom of the primary tank. For the remainder of the $51 / 2$ hours no significant changes were observed and the test was terminated. The anomalous increase in power is attributed to the differential expansion of the primary tank relative to the control rod extensions and/or the safety rod support rods. As explained above, this differential motion can add reactivity to the system. Such an addition in reactivity would cause the reactor power to rise and heat up the primary tank, as seen in the animation, until the rising reactor temperatures removed the added reactivity. While this model provides a reasonable explanation, it has not been explored in detail.

UNPROTECTED LOSS - OF-FLOW TEST

The unprotected loss-of-flow, LOF, test was started from the same initial conditions as the above LOHS test and represents a serious accident in which the plant protection system fails to initiate a scram. The LOF test was conducted twice, SHRT 45 on February 12, 1986 and a SHRT 45R on April 3, 1986. This test is thoroughly described and extensively analyzed elsewhere ${ }^{5}$. While the reference emphasizes SHRT 45, we chose to emphasize SHRT 45R because both temperature probes were in the primary tank for this test.

This transient was initiated by removing power to the two main primary coolant pumps and the secondary pump. This caused temperatures within the 
reactor to rise. The rising temperatures decreased the reactivity in the system and therefore caused the reactor power to decline. This ultimately caused the rising reactor temperatures to reverse as the reactor power went to a few per cent of its initial value. The primary pumps coasted to a stop about $100 \mathrm{~s}$ into the transient and the peak reactor outlet coolant temperature al so occurred early in the transient.

The animation for this test showed a rapid increase in the temperatures in the upper portion of the tank while the temperatures in the lower portion significantly decreased as compared to the 09:00 steady-state profile, figure 6 . This behavior of the upper portion is attributable to the large increase in reactor outlet coolant temperature early in the transient. This substantially heated up the reactor outlet pipe which increased the rate at which heat was conducted to the surrounding tank sodium.

It is apparent that the temperature of the primary sodium exiting the IHX dropped during the transient and the greater density of this cooler fluid caused it to fall toward the bottom of the primary tank. This would explain the reduction in the temperature observed in the lower portion of the tank. A drop in IHX primary outlet temperature normaliy results when the heat removal rate of the secondary-loop flow exceeds the heat generation rate of the reactor.

At about 25 minutes into the transient, the control rods were lowered and the primary pumps were restarted. This stirred up the fluid in the primary tank and resulted in a uniform temperature in the primary poo1, as shown in figure 6 .

A good mental picture of the transient behavior of the temperatures within the primary tank, as provided by an animation, can significantly aid the understanding of complex phenomena. Although the temperature of the sodium exiting the IHX was decreasing, the temperature of the sodium entering the 
primary pumps could have been increasing. This is because the primary pump inlets are at a different elevation within the tank. However, when the pump inlet temperature is rising the reactor inlet temperature may be falling. This is because the reactor inlet pipes extend down through much of the depth of the pool from the pump inlets to the reactor inlet plena. At very low convective primary flow rates, the small amount of heat lost via conduction along an inlet pipe can have a very significant impact on the temperatures inside it.

\section{COVER LIFT TEST}

The plant system experiments (PSE-3) were intended to investigate the behavior of the hot pool of an LMR and heat transfer to an external air cooling system. These tests were to provide data for code validation of the COMMIX computer code in support of the concept of a Reactor Vessel Auxiliary Cooling System (RVACS) such as has been proposed for the PRISM reactor.

The EBR-II shield cooling system cools and recirculates air through the air baffle tank surrounding the primary tank to maintain acceptable biological shielding temperatures, figure 9. Given the design of the shield cooling system, the experiment utilized forced convection rather than the natural convection of the RVACS design.

The single EBR-II pool was used to simulate the hot pool of other LMR designs. It was initially assumed that with the reactor cover in the up position, the thermal plume exiting the upper plenum would behave like that of a hot pool. The sodium in the pool was expected to be drawn into the pump intakes and pass through the reactor core via natural circulation. With the reactor cover in the up position and the secondary flow reduced to $0.5 \%$ of 
$-13-$

nominal, the IHX heat transfer was expected to be minimal. The process was expected to continue in a transient manner with a gradual heat up of the bulk sodium until the decay heat generation was less than the sum of heat removal by the shield cooling system and other parasitic heat loss.

The test occurred at the end of a normal 45 day reactor run to maximize available decay heat. Following a reactor shutdown on November 17, 1986, the two main primary pumps were secured. Under this condition $3 \%$ to $5 \%$ flow is provided by the auxiliary pump with the aid of natural circulation. Figure 10 shows the development of the tank temperature profile once the primary pumps are shut off at $05: 48$. Even with some forced convection, the decay heat is sufficient for a small temperature gradient to be established within the primary tank within a few minutes, curve 06:00 and 06:20 in figure 10. The animation shows small traveling perturbations in the axial tank temperature profile. A "snapshot" of these perturbations appear as a jog in the temperature profile between $4.2 \mathrm{~m}$ and 5.6 $m$ at time $06: 20$ in figure 10. In the animation these perturbations appear to result from some form of bulk movement of sodium within the tank.

Preparations to raise the reactor vessel cover required approximately nine hours since the preparations are the same as those for unrestricted fuel handling. Several restrictions were placed on the plant to minimize various heat sources and sinks. The primary tank heaters were secured. The shield cooling exhaust fans were secured so that most of the shield cooling flow was directed through the recirculation path where a heat balance could be performed. The secondary flow was reduced to its minimum value of $0.5 \%$.

Thirty minutes prior to raising the reactor cover, the primary pumps were restarted for a few minutes to mix the sodium pool and create an initial flat temperature profile. Then the auxiliary and both primary pumps were stopped. 
The raising of the reactor vessel cover commenced at 10:47 to allow the hot sodium in the upper plenum to exit directly to the pool. The raising of the reactor cover was completed at 11:00. Much of the effect on the temperature profile associated with the cover up position occurred while the cover was being raised as can be seen by comparing curve $11: 00$ and 17:00 of figure 11 .

The data showed the thermal stratification in the primary tank which virtually disappeared when the primary pumps were restarted. After the pumps were stopped, the stratification was reestablished, curve 10:45 of figure 11 . Heating of the upper portion of the primary tank was observed shortly following the cover lift. However, significant flow through the reactor core did not occur as indicated by the flow meters located in the inlet leg of the No. 2 primary pump. The flow path that was established cannot be completely defined based on the available data but it is speculated that fluid entered the upper plenum radially and rose as a thermal plume. There may have been some secondary flow patterns either in the expanded plenum region or inter-channel flow within the core but there was not sufficient instrumentation to determine this.

Another aspect of the flow that was notable was that the behavior of the thermocouple probes differed significantly from each other in this experiment, whereas in the SHRT tests the probes were close in response. The F-probe was essentially quiescent during the entire test and had a fairly uniform temperature gradient. The G-probe exhibited approximately the same temperatures at the top and bottom of the urobe as did the $F$-probe but the temperatures in the middle to upper portion varied considerable with time. There were two patterns alternating in the G-probe temperature profile. One of these patterns had a uniform gradient similar to the F-probe. The other pattern had a section with almost a zero 
temperature gradient extending for varying axial extents. The second pattern may have been the result of mixing as the fluid moved axially.

\section{GENERAL OBSERVATIONS AND CONCLUSIONS}

The temperature probes provided a window from which one could obtain a unique view of the behavior of the primary tank. The probe temperature profiles for steady-state power conditions provided considerable insight. The most significant findings were that 1) most of the action tends to be in the upper half of the tank where the IHX outlet and the pump inlets are located and where the reactor outlet pipe raises local temperature significantly and 2) although the temperatures in the bottom half are fairly uniform, there are considerable thermal $f$ uctuations in both halves of the tank.

Although the probes are on opposite sides of the tank, they have very similar axial temperature profiles in all but the cover lift test. Hence, while dynamic models of the primary system need to take into account the distinct behavior of the upper and lower regions of the pool, side-to-side differences may be less important.

The animation software did more than add convenience. Observing axial temperature profiles deform and move across the computer screen at a speed proportional to real time, one develops new hypotheses. Sometimes the same transient was viewed again and again, with stops (i.e., freeze-frames) along the way, as theories were formed and tested and then confirmed or discarded. Moreover, the temperature profiles which were presented in the preceding figures were selected by viewing the tenperature animations of the tests. 
$-16-$

\section{ACKNOWLEDGMENTS}

Work supported by the U. S. Department of Energy, Office of Technology Support Program under Contract W-31-109-Eng-38.

\section{REFERENCES}

1. G. H. GOLDEN et al., "Evolution of Thermal-hydraulic Testing in EBR-II", Nucl. Eng. Des., 101, pp. 3-12 (1987).

2. L. ADAMS, High-Performance Graphic in $C$, Animation and Simulation, Windcrest Books, Blue Ridge Summit, PA, (1988).

3. Turbo C, Version 2.0, Borland International, Scotts Valley, CA (1988).

4. E. E. FELDMAN et a1., "EBR-II Unprotected Loss-of-Heat-Sink Predictions and Preliminary Test Results," Nucl. Eng. Des., 101, pp. 57-66 (1987).

5. D. MOHR et al., "Loss-of-Primary-flow-Without-Scram Tests: Pretest Predictions and Preliminary Results", Nucl. Eng. Des., 101, pp. 45-56 (1987). 


\section{List of Figures}

Figure 1: EBR-II Primary System

Figure 2: Reactor Cover Position

Figure 3: Thermocouple Probe Locations

Figure 4: Full Power and Shutdown Axial Temperature

Figure 5: SHRT B302 Temperature Profile Development

Figure 6: SHRT B302 Late Temperature Increase

Figure 7: SHRT 45R Temperature Profile Development

Figure 8: SHRT 45R Temperature Profile Collapse

Figure 9: Shield Cooling Paths Around Primary Tank

Figure 10: Decay Heat Level Temperature Profile Development

Figure 11: Cover Lift Test Temperature Profile Development 


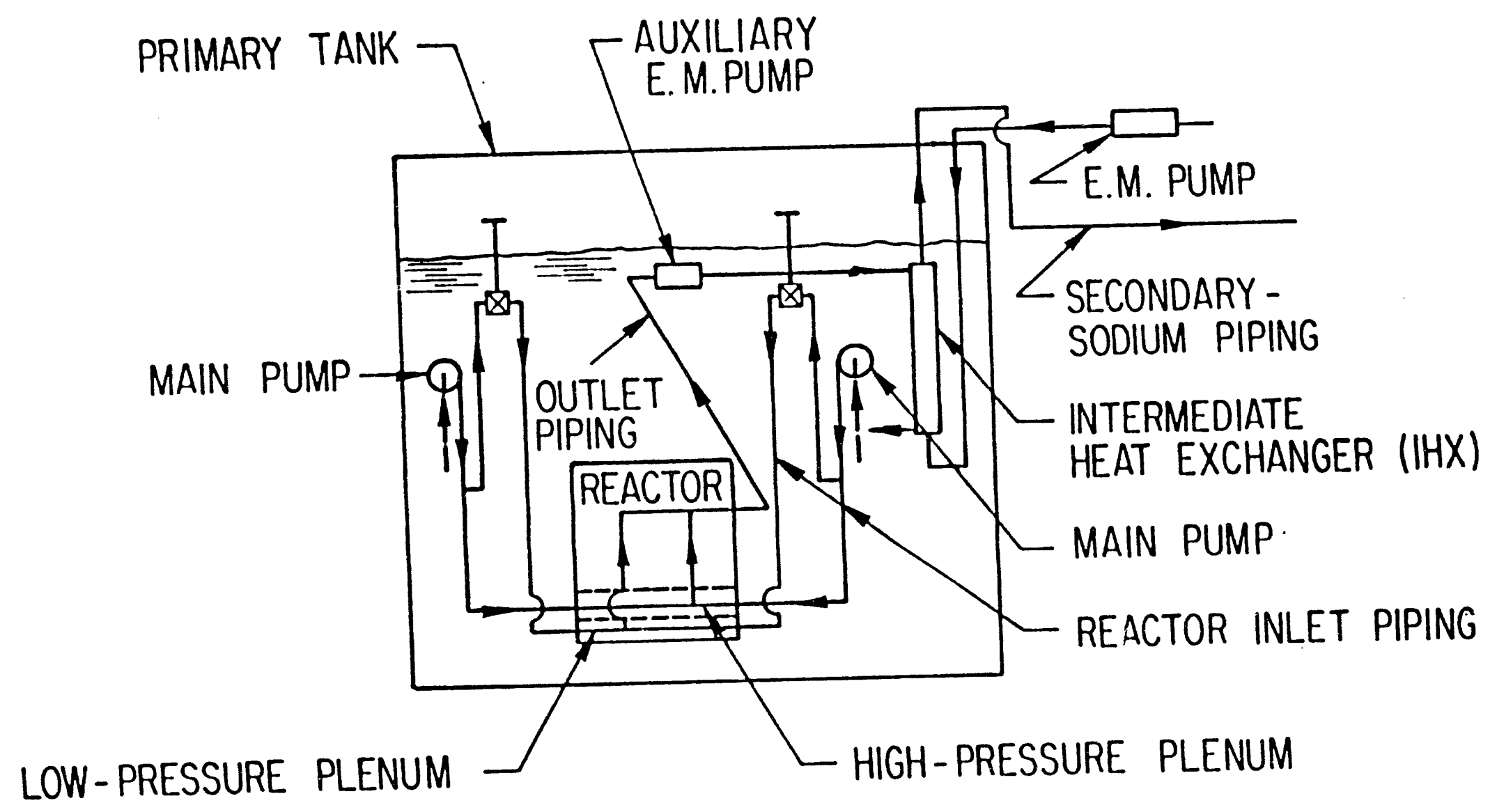




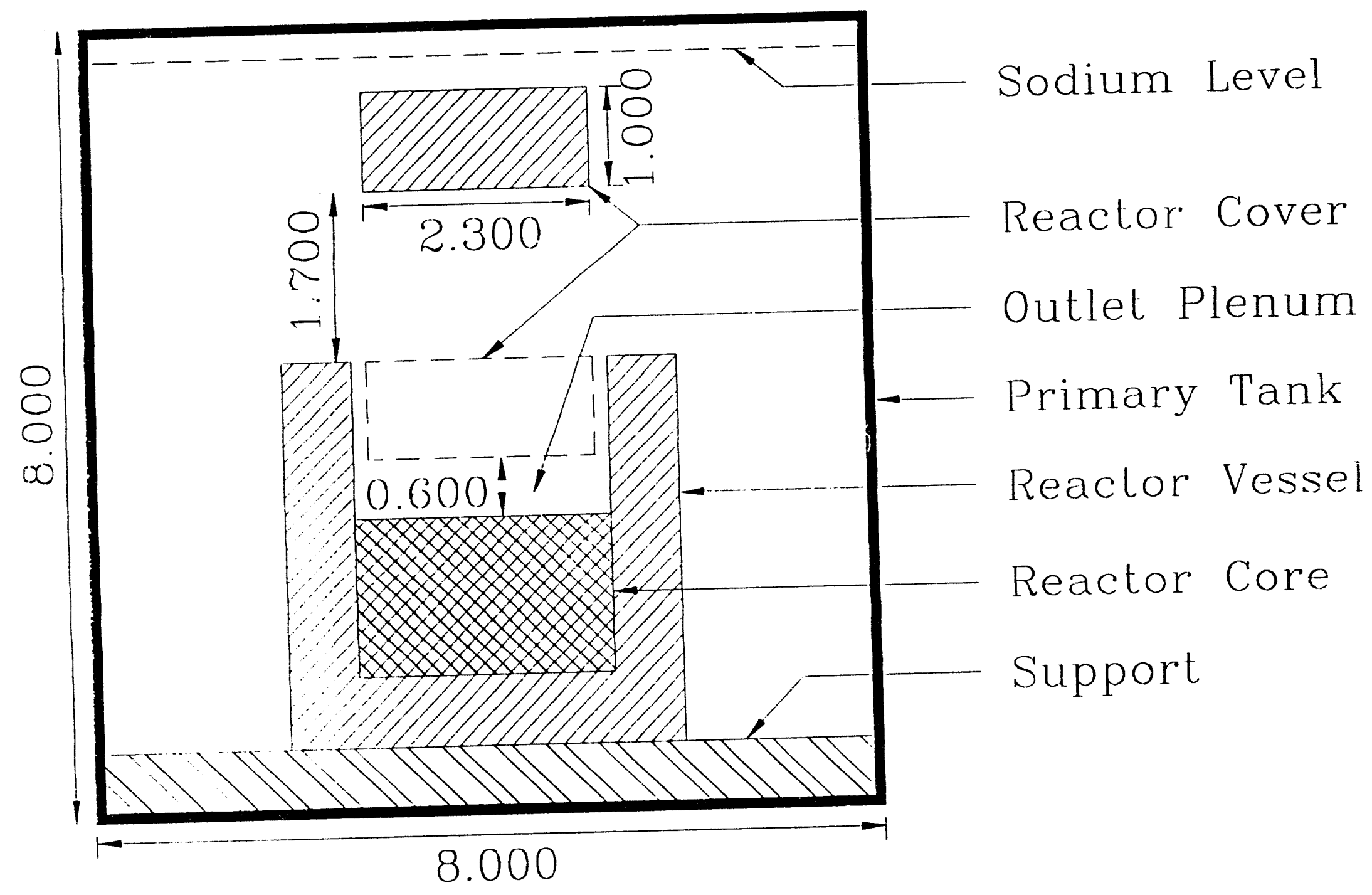




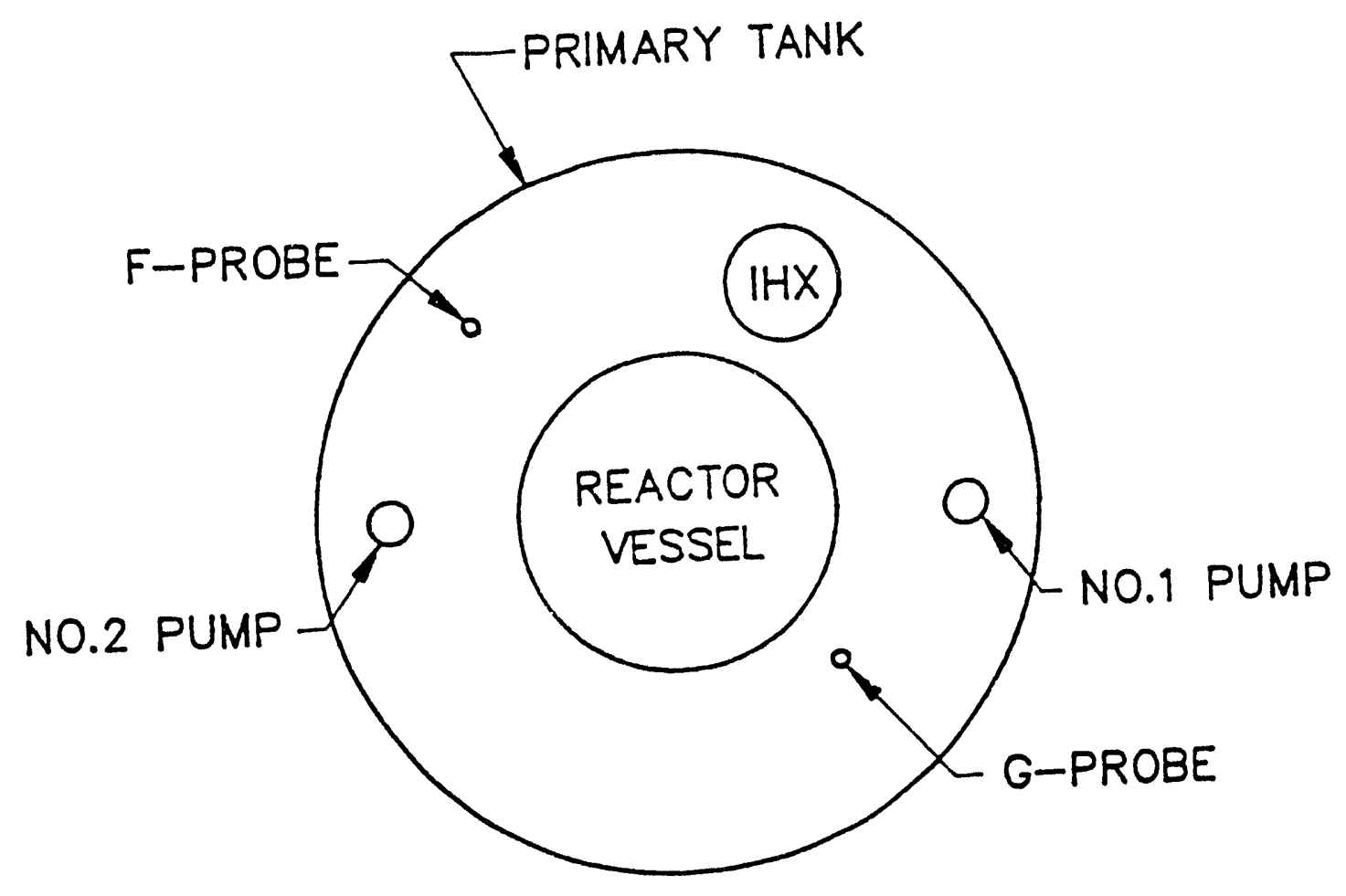




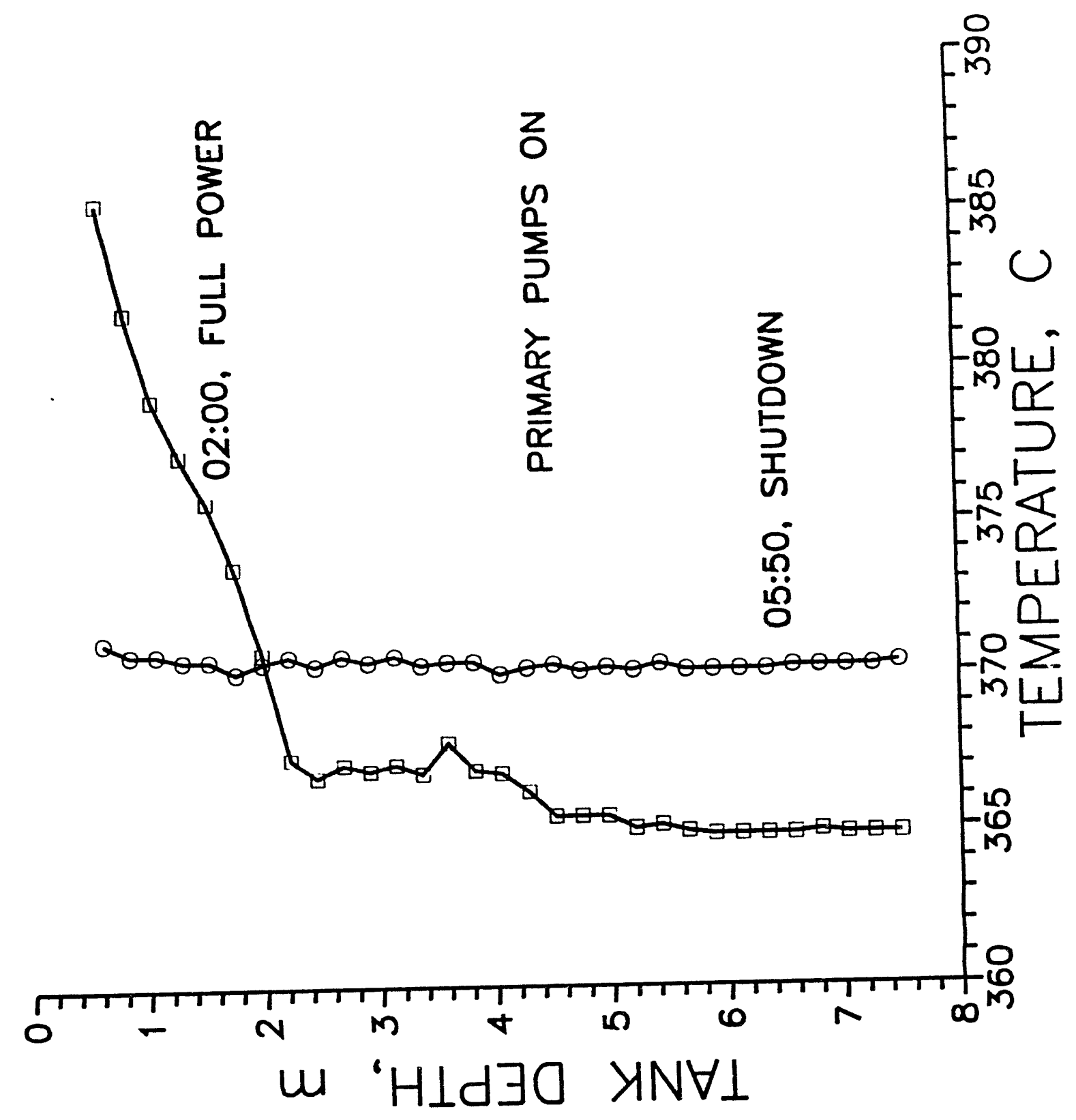




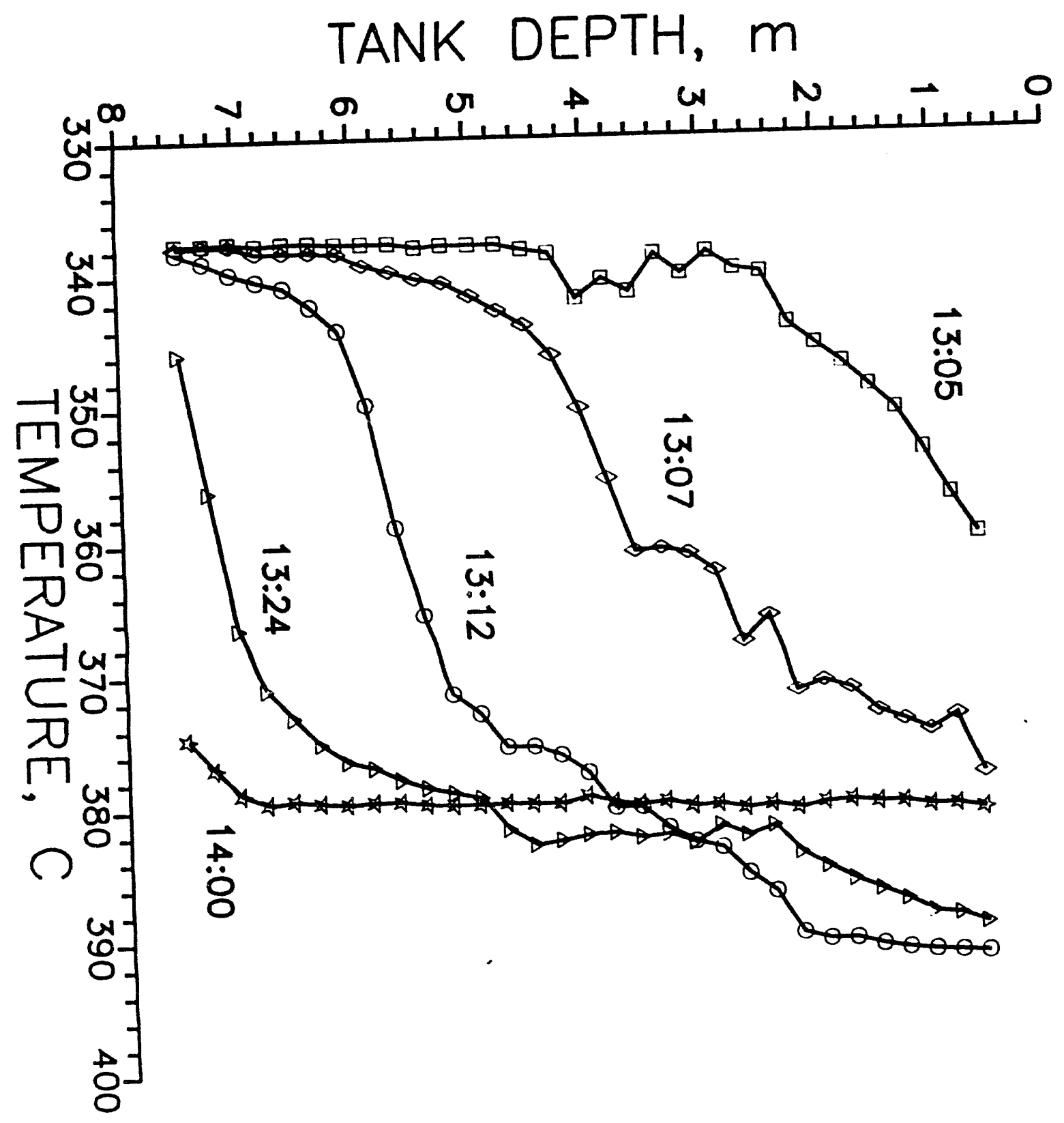




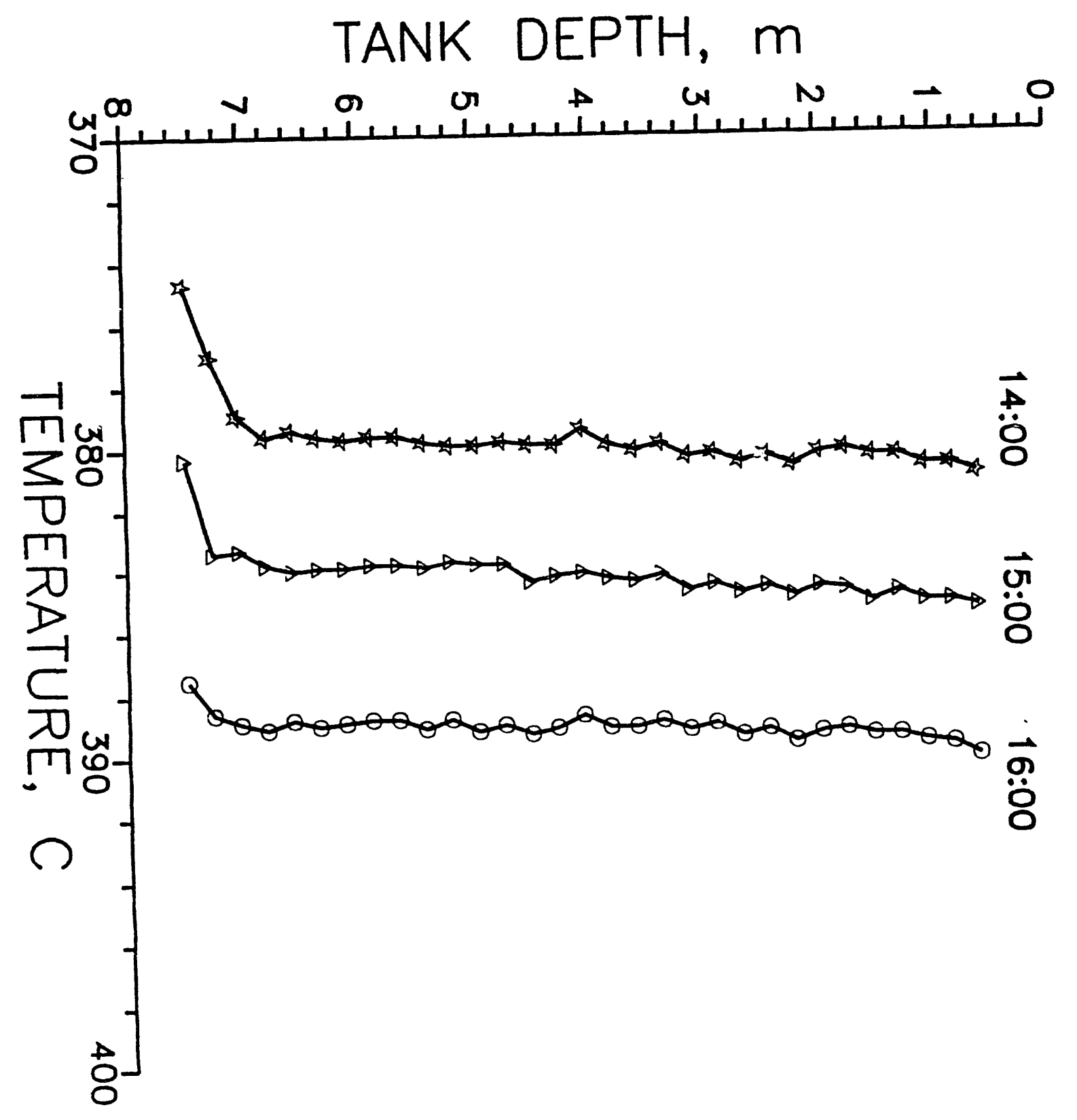


TANK DEPTH, $m$

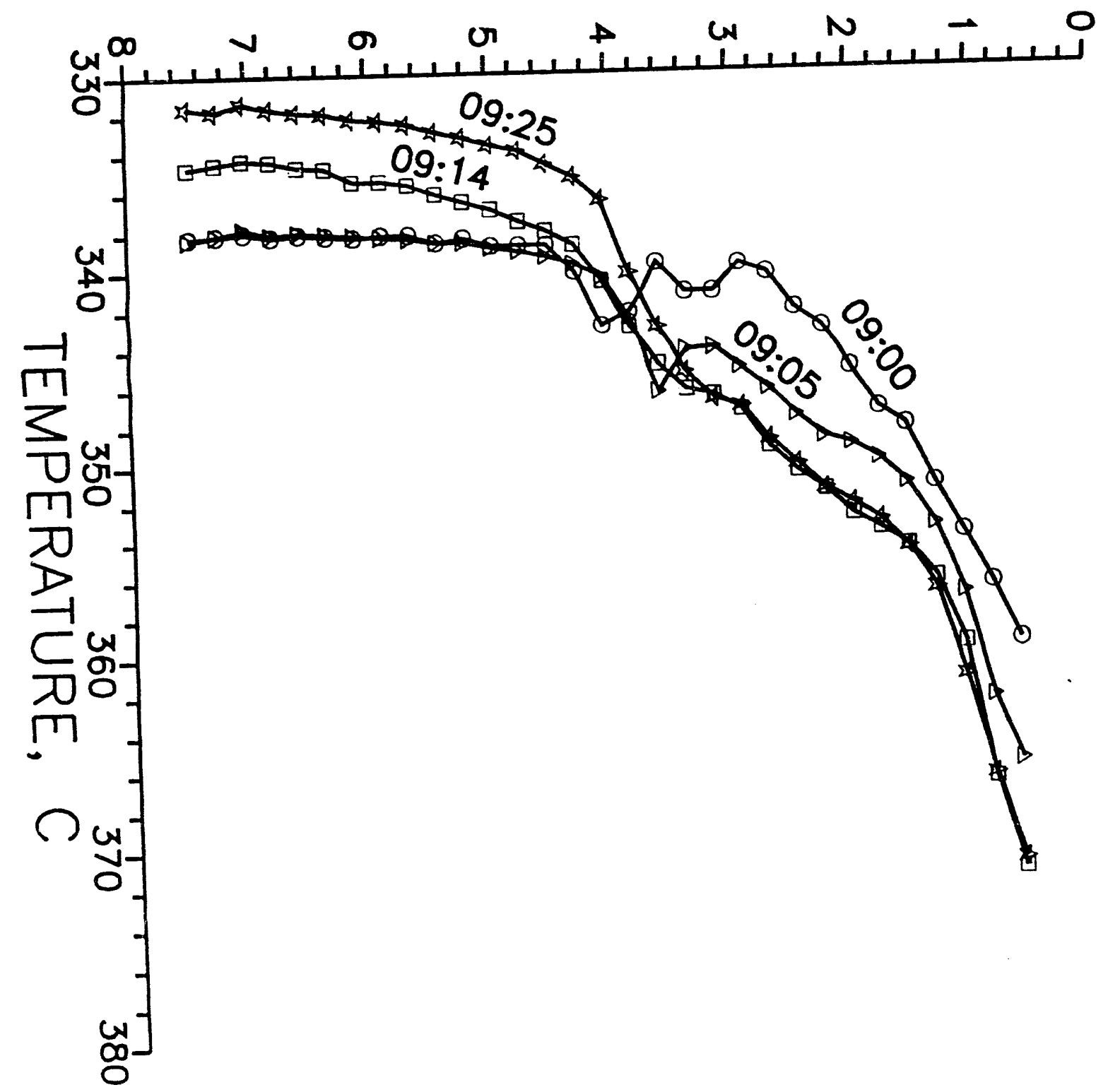




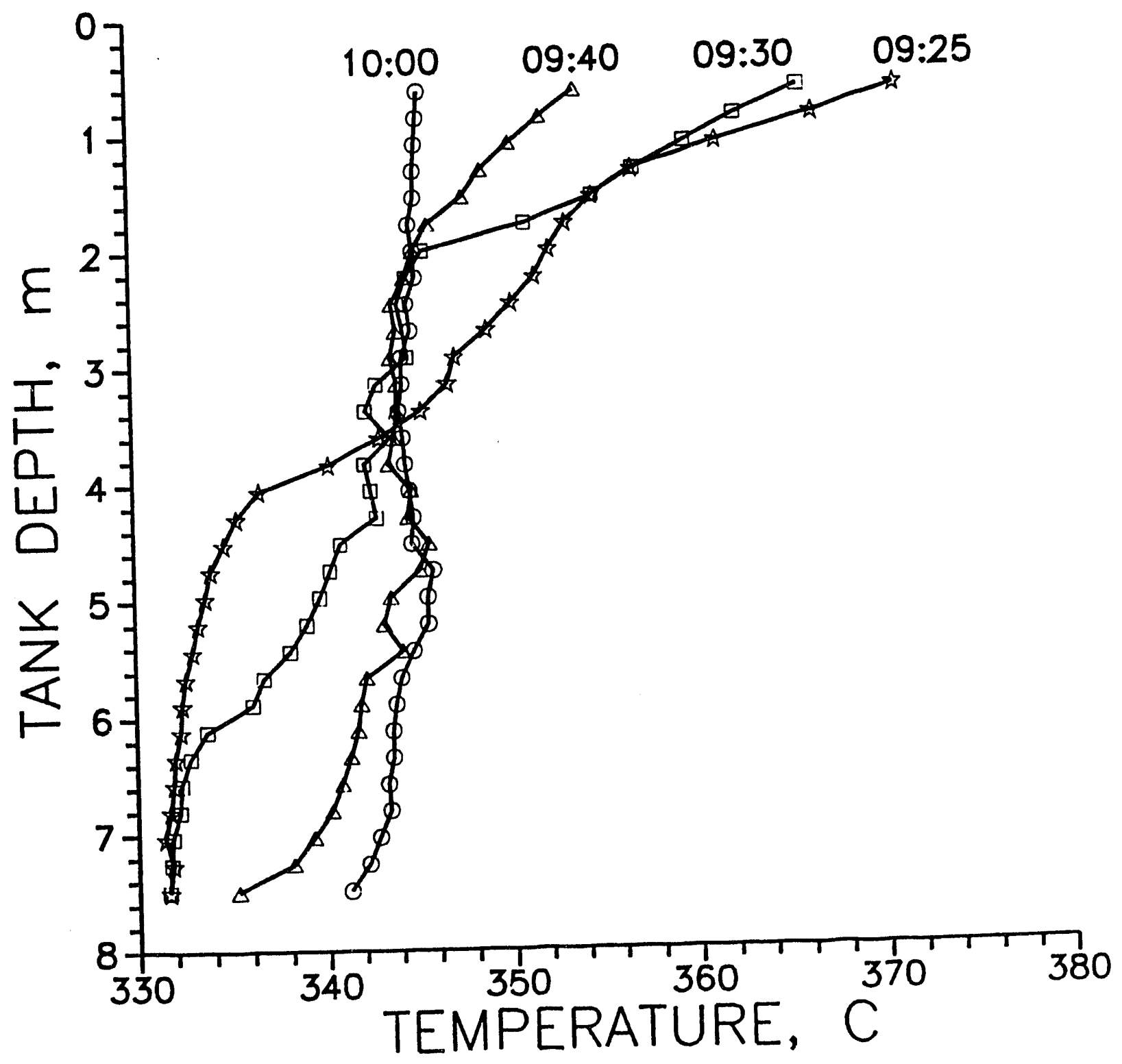




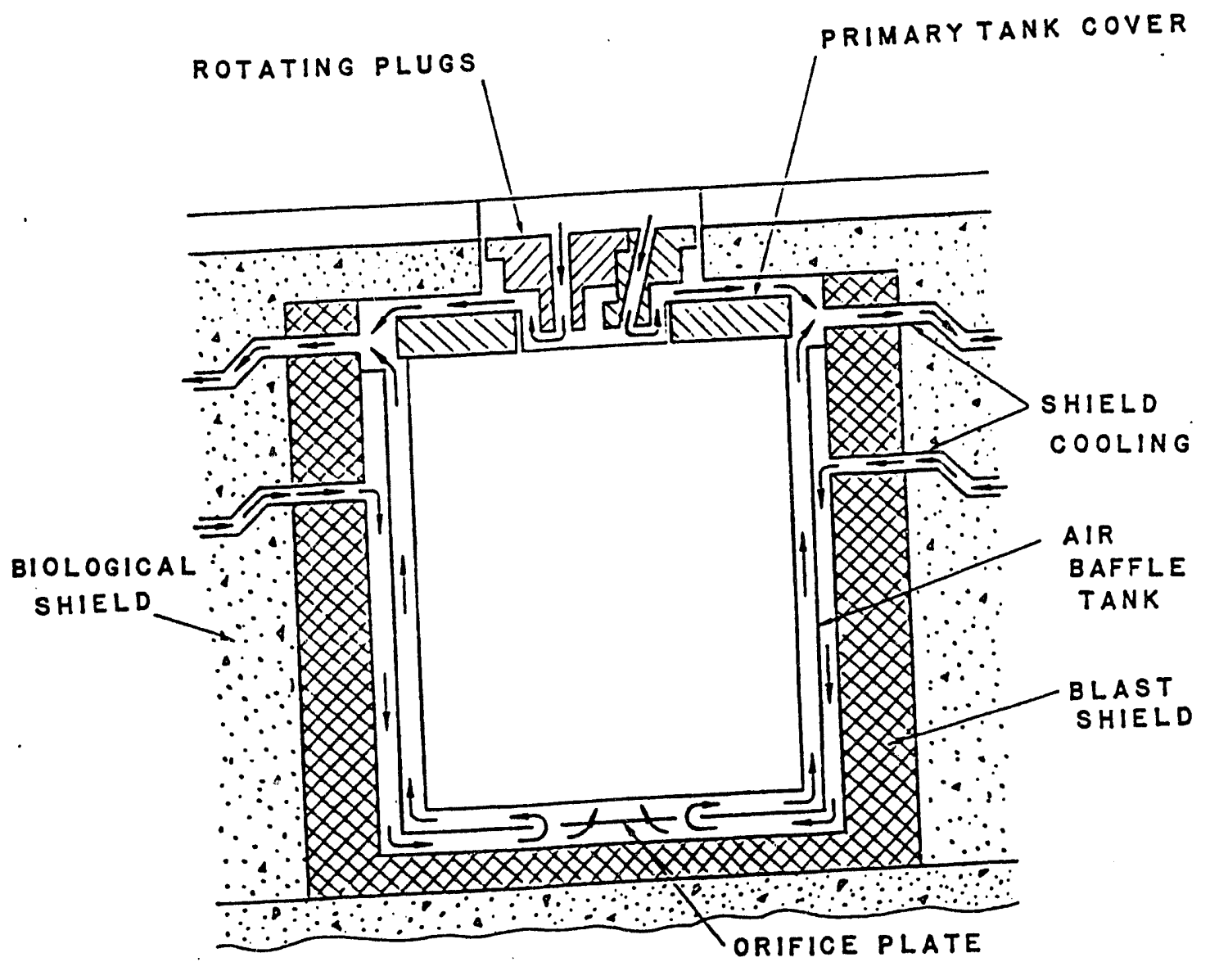




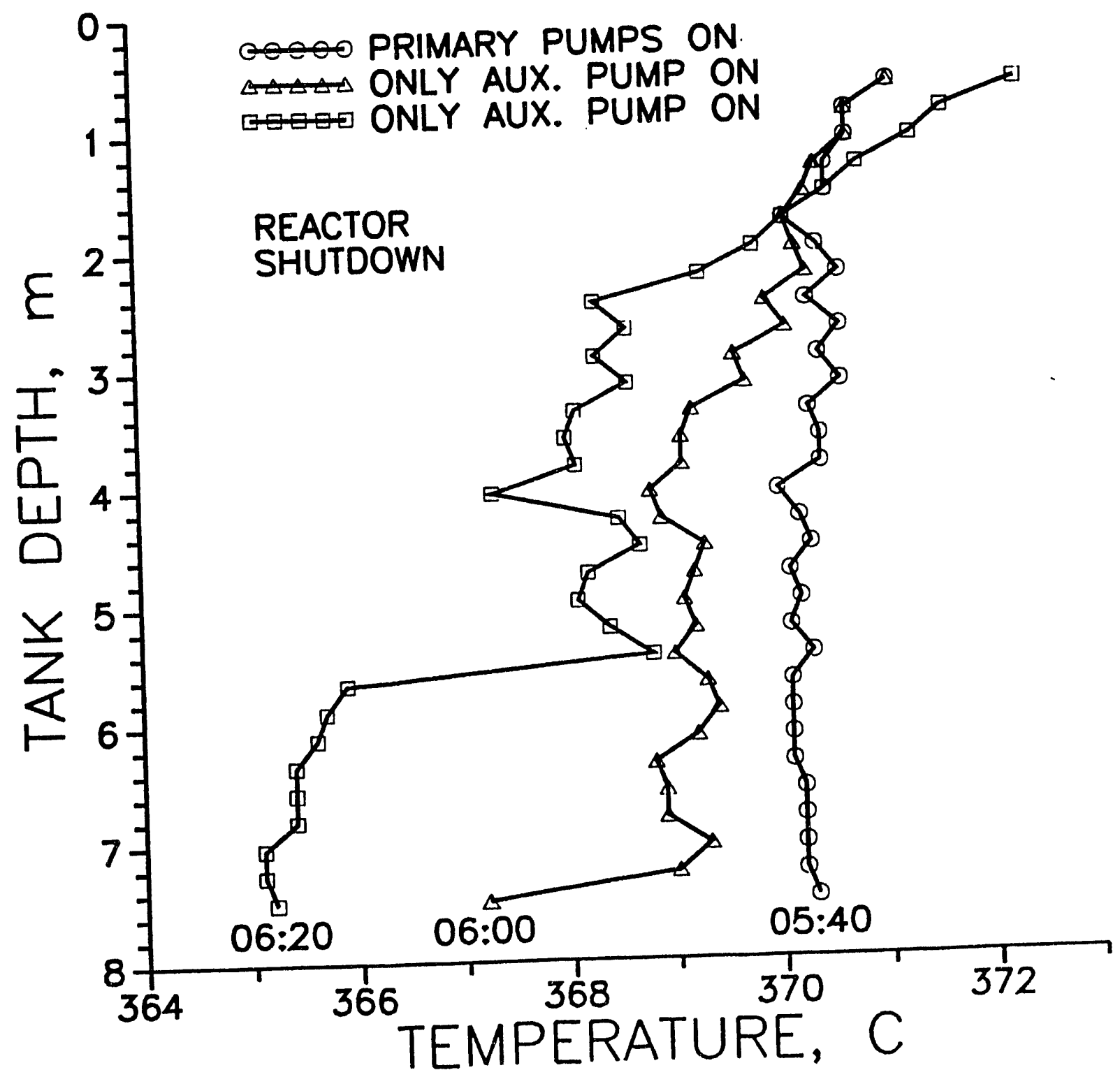




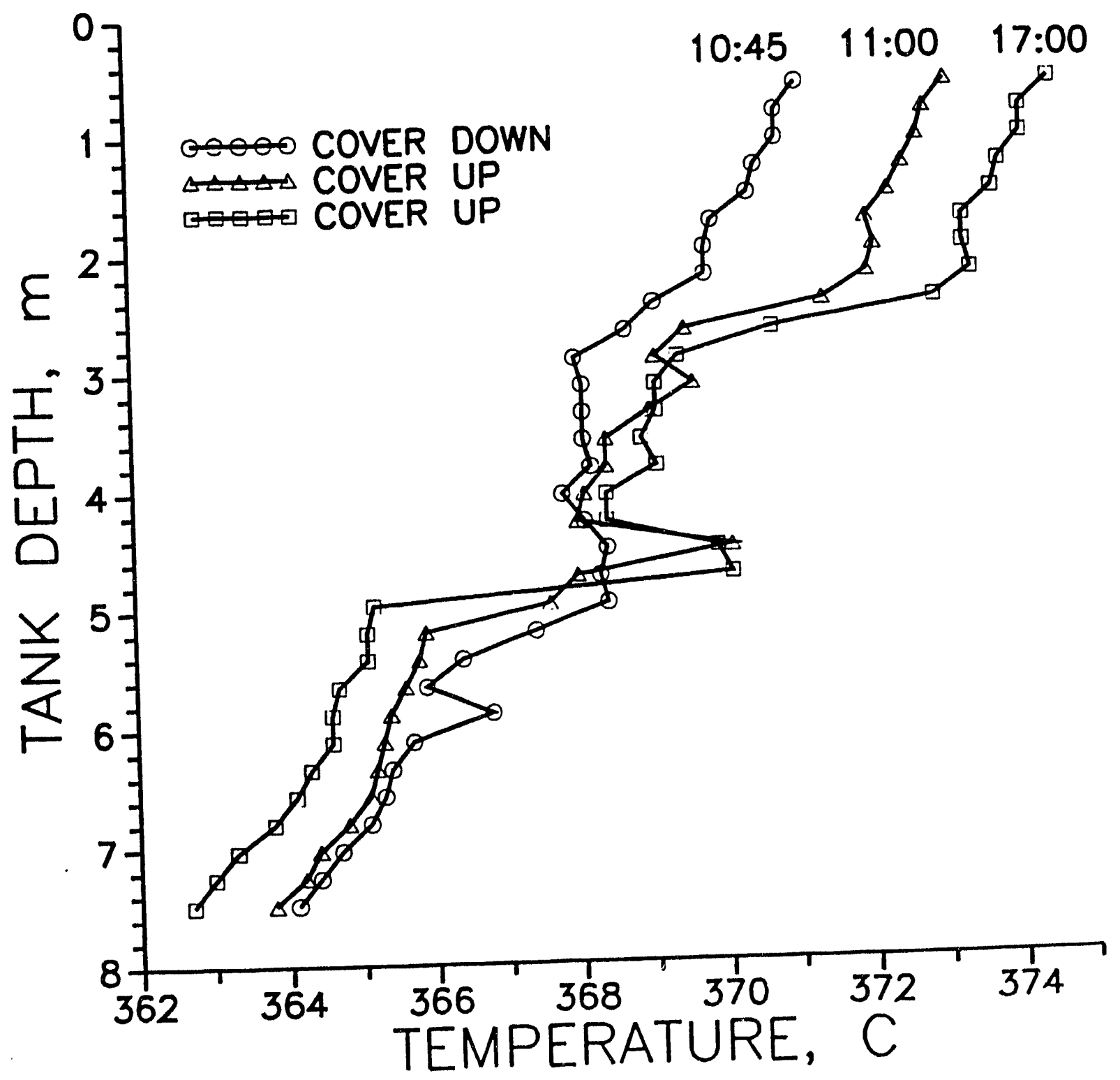




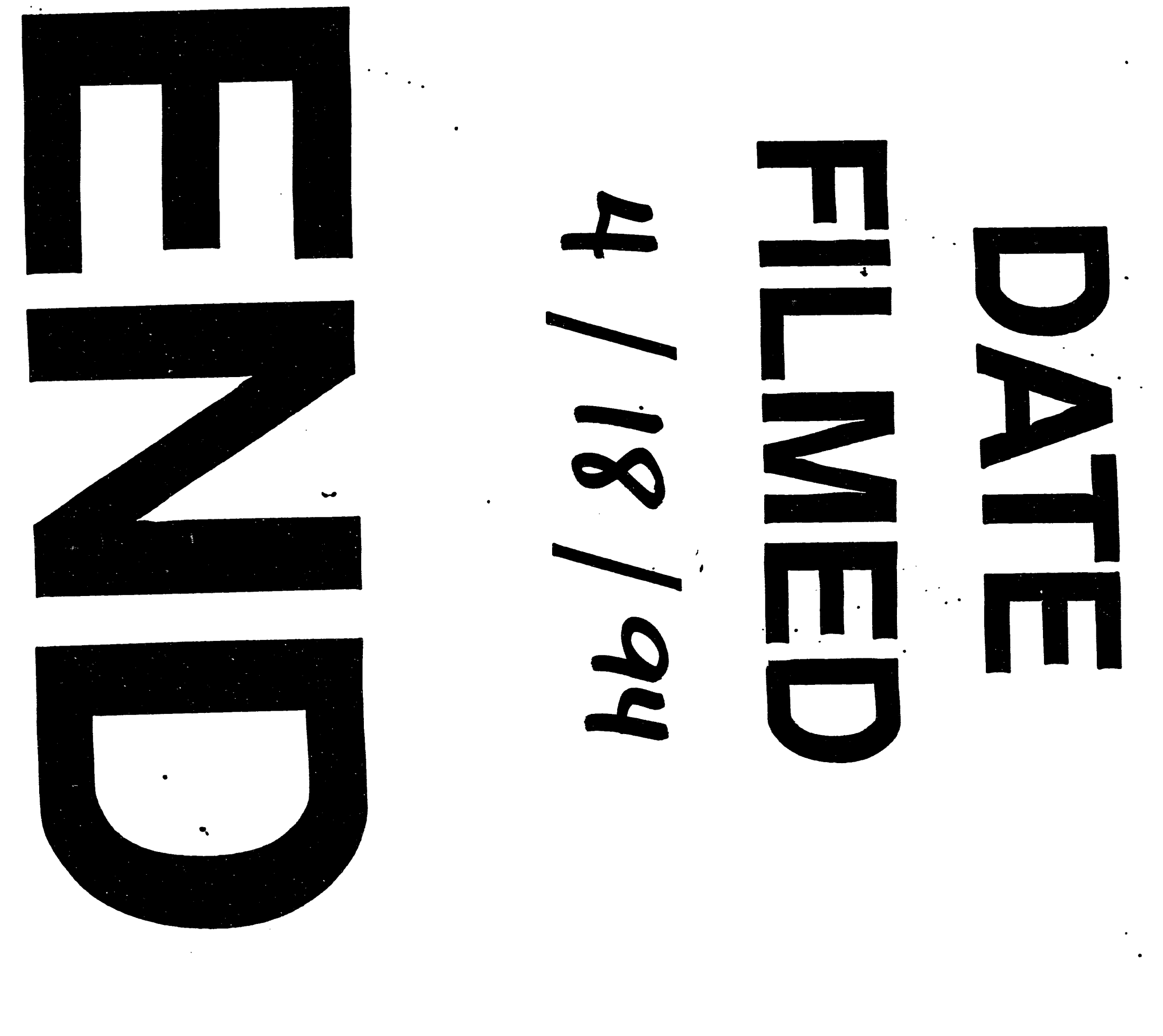


